\title{
STREET PAVEMENTS.
}

[Contribution from the Department of Civil Engineering, Towne Scientific School, University of Penna.]

By Prof. Lewis M. Haupt.

Since the days of MacNeill, Telford, McAdam, Parnell and others, volumes have been written upon this subject, yet we have in many localities pavements which are a disgrace to a community making any pretentions to scientific knowledge.

This results either from a misunderstanding of all the conditions of the problem or an inability to fulfil them. The conditions, it is true, are intricate and variable, depending on location, grades, nature of merchandise, vehicles, power, subsoil, finances, etc., but in this monograph we propose to discuss briefly only the requirements of the surface covering, and to determine in the light of a long and varied experience what material will best fulfil all the conditions of a crowded thoroughfare.

The requirements of the surface are that it shall be: (1) firm and elastic ; (2) noiseless, clean and dry ; (3) smooth, yet rough; (4) permanent, yet easily removable; (5) light, yet heavy; (6) it should be durable, producing a minimum amount of wear and tear; $(7)$ it must also be cheap and readily obtainable, and (8) non-combustible.

The impossibility of selecting any one of the available materials, wood, stone, brick, cement, iron, or asphalt, which will fulfil all the above conditions, is apparent. A compromise must therefore be made, and one or more selected which will approximate most nearly to the requirements of the case.

It is interesting to observe the ingenuity displayed by advocates of a particular material, in making it conform to every want, and in theory all of the above materials have been found to answer equally well, but from a practical, rational and disinterested point of view it is impossible that such should be the case; e.g.:-

Vegetable Substances, containing within themselves nitrogenous principles, elements of decay and putrefaction, should be rejected from sanitary considerations alone, but in addition to this their combustibility, softness of fibre, permeability and cost, are serious obstacles, and the experience of numerous trials on both continents, under varied

Whoum No. Vol. CIII.-(Third Skrme, Vol. lxxiii.) 
conditions, has prover them failures as to durability. We feel entirely justified, therefore, in omitting this material from the list of available substances until some more efficient means be successfully introtuced of preserving the blocks, draining the foundation and preventing dry rot.

Iron has been used in various forms, but being a manufactured article, it is more expensive than stone or wood which are natural products. Hexagonal and other forms of blocks, covered with studs, and standing on legs which were driven in to the foundation, have been diccarded because of the noise, expense and insufficient foothold. Wherever tried in the form of blocks, iron has been found very objectionable, and its use is now restricted to tram and railroads.

Bitumen is a natural mineral product, belonging to the class of bydrocarbons, and may be found either solid, as in asphaltum, or liquir, as in mineral tar. It is used chiefly as a matrix for harder materials.

The best asphaltum is imported from Scyssel, in France, and Neufchâtml, Switzerland, but a tolerably good article is also obtained from the iwland of Trinidad. This substance melts at a comparatively low temperature, and is quite brittle when cold, so that it possesses properties which render it inappropriate for roads when subjected to sreat ranges of temperature and heary traffic. When used, however, wirh and and cement it forms an excellent suface, so far as smoothness and durability are concerned.

The wooden pavement on Ponnsylvania Avenue, Washington, has recutly been replaced by another, part of which is composed of Neufclatel bituminous limestore, one and three-quarters inches thick, laid on a foundation of eight incties of cement, and the remaindur of "Gruhamite" (pure asphalt from Ritchie County, Va.), two and a balf inches thick, on a sirnilar foundation. ${ }^{\mathrm{i}}$

$B r i \cdot k$, being merely clay irdurated by burning, is too brittle for ordinary travel. We find ourselves, therefore, restricted to the use of stone or cement as fulfiling most nearly the requirements of a good road covering.

But Stone occurs in a variety of forms, as in "cobbles," boulders, "spalls," or blocks, and in sizes which vary as the ratios of their three dimensions. Of the three first mentioned forms it is difficult to docide

1. Letter of Gen'l Q. A. Gillmore, and his work on Roads and Street Payements, page 182. 
which is mos injurious, yet these are the favorites with the community, because of their cheapness (?), and with the contractors, hialue of the propertionately large margin of profit, and necessity of frequent repairs. By this general and brief analysis we are induced to bulieve that stone of a regular geometrical form is that which is most suitable for the purpose; cement being an artificial monolith, whose dimensions may be externted at pleasure, is included in this class. It is not intended to review in detail the whole question of the adaptability of the various materials to the object in view, as this has alrealy heen done in an exhaustive and able report of forty-one pages, made by eight eminent engineers, ${ }^{1}$ and published in the Jourval of September, 1843 , but to review and emphasize the conclusions therein deduced. It was recommended to use a pavement of "dressed stone," lair diagonally upon a foundation of concrete, in those squares where the sewers and various supply pipes were completed, and to lity stone tramways on the steep gradients from Front Street down to Delaware Avenue. These are substantially the conclusions we are forced to adopr, -ven after the litpse of these thirty-four years, yet in all this time ihey seem to have gained but little ground.

A tramway in connection with a "Belgian" block system woul? fuifil all the requirements in the best and most economical manner. 'l'rams, eight inche's deep, and two feet wide, if well laid, would oppowe the least possible resistance to the wheels of vehicles, and would be nuiseless, whilst the blocks between would furnish the desired footholi, and the clicking of the horse's feet give sufficient warning of the appro:ching vehicle.i This arrangement supposes the conditions of the horse and carriage to remain constant, and until lately it has been asianed that these elements of the problem were fixed, but rubber tirs iave been introrlueed and give great satisfaction. Still the rouglisin of the pavemont required to furnish the necessary foothold has becen fiund

'The menhers of this committee appointed by the Franklin Institute Jiti" $2: \mathrm{th}$, 1843, to report to City Councils on "'The best modes of paving highways," were: Lwoonl Morris.

Jno. C. T'ratutwine. George W. Smith, decensed. Henry R Cumpbell. Solomon W. Roberts. Jos. Suxton. M. T. W. Chandler, deceased, Sam'l V. Merrick, decensed.

it Tram stones of the above dimensions ean be furnished and lail, of Old Dontinion granite, at a cost of $\$ 3.25$ per lineal yard, whilst Belgian blocks, covering the s:mo surfice, are wurth $\$ 2.25$, making the trams cost one dollar more per yard, but every other consideration is in their favor, and ultinately they are cheaper. 
to cut and destroy them so rapidly as to render their general introduction improbable. If now we can substitute for the present shoe a material that will prove as durable and as secure, at the same cost, it will open the way to great reforms in all the elements of locomotion, viz.:- the pavement, the vehicle and the power,

Such an improvement has indeed been made and tested satisfactorily. It consists of a hollow shoe of the ordinary shape, open at the bottom, and having iron studs projecting vertically downwards tbrough a threequarter inch tarred rope which they hold in place, and which serves as a packing. The shoe is put on without heating and held in place by six nails. It has been used until worn down to a kuife elge, and its life is quite as long as that of the ordinary iron shoe. The rope is not kicked out by use, but is in fact riveted firmer by the pounding down of the studs. ${ }^{i}$

The general introduction of such an improvement would undoubtedly lead to the substitution of concrete for the rumbling rubble pavements now in use. The chief objection, lack of sufficient foothold, having been overcome, minor difficulties need have but little weight, as that portion of the surface overlying sewers, etc., might be divided in to blocks which could be readily removed and replaced. The necessity of breaking the surface for pipes could easily be avoided by laying them hereafter under the sidewalks or in rear of the dwellings, in streets of the second class.

There is a street in Philadelphia (a short one to be sure), upon which there is no railway, and whenever a wagon or cart passes at a trot it shakes all of the buildings, which are said to be substantial. What must be the waste of energy that will set in vibration the houses on both

i The sketch below indicates the outline of this shoe. It is cast of malleable iron, of the usual shape of a horse-shoe, having its lower face open, into which a slip of tarred rope is presser of larger diameter than the width of the opening; a range of prongs lises in the centre of the eavity which pierce the rope, and thus uniting with the stress from the sides, hold the hemp firmly. The shoe partakes somewhat of the moccasin and also of the sandal; it absorbs concussion and retains friction, and embraces conditions of fitness such as I never saw associated before.--II. 0 .

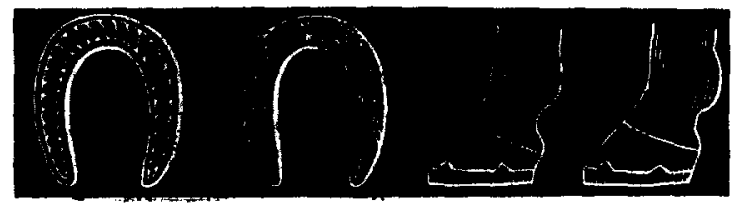

Under surface. Upper surface.

Shoes in position. 
sides of a street whenever a vehicle passes? Yet the injury is not limited to the vehicle, the edifice, nor the road covering, all of which are badly shaken up, but extends in a greater degree to the animal life affected by it: the horse, and the individuals in the house or conveyance. It is a constant strain upon the nervous system of women, invalids and children whose sleep is disturbed and restless. The racket is especially noticeable by visitors from rural districts, who are unaccustomed to such a continual jarring. This enormous waste of energy can and should be avoided by recourse to proper engineering expedients, and no one will deny that a uniformly smooth, even and continuous surface, such as that furnished by a good cement pavenent, with only joints enough to permit of expansion, would fulfil in the most perfect manner all the requirements for the horse, carriage, passenger and resident, could be kept perfectly clean, and when once laid would require the minimun amount of expense for repairs and police.

Before closing there is another point which is worthy the consideration of the enterprising and progressive citizen, and that is the large amount of space wasted by front steps. In many streets at least half the footwalks are interrupted by sucb projections, forming useless dead spaces between them which serve to collect the snows of winter, to be piled up in the street, forming impassable obstructions for a considerable length of time. The steps themselves, exposed as they are, become dangerous from ice, and are not an architectural necessity nor ornament. Every consideration of humanity would suggest their being withdrawn, and, when necessary, occupying the place of the vestibule, leaving an open recess or niche in the place of the outer door. Thus the visitor or resident would be sheltered from sun, wind, min or snow whilst waiting the answer to his summons; the steps widald not be dangerous by being coated with slect; the suggestion of hos;itality would be extended by the apparently open door, which effect would be heightened by an outside lamp at night, and the full brealth of the sidewalk left available for a promenade, with rows of trees, if desired. The plan is not a new one, but is in use in many cities of this country and the continent.

Carbon for Electric Light.-M. Th. du Moncel forms a compressed mass of carbon and magnesia, which is very hard and burns wirhout nsh, giving a light which is steadier and 34 per cent. more intense than that of gas carbon.-Ex. 